\title{
Simultaneous growth of self-patterned carbon nanotube forests with dual height scales $\uparrow$
}

\author{
Ebru Devrim Sam, ${ }^{a}$ Gokce Kucukayan-Dogu, ${ }^{b}$ Beril Baykal, ${ }^{a}$ Zeynep Dalkilic, ${ }^{a}$ Kuldeep Rana ${ }^{a}$ \\ and Erman Bengu*a
}

\author{
Received 2nd February 2012, Accepted 17th April 2012 \\ DOI: $10.1039 / \mathrm{c} 2 \mathrm{nr} 30258 \mathrm{f}$
}

In this study, we report on a unique, one-step fabrication technique enabling the simultaneous synthesis of vertically aligned multi-walled carbon nanotubes (VA-MWCNTs) with dual height scales through alcohol catalyzed chemical vapor deposition (ACCVD). Regions of VA-MWCNTs with different heights were well separated from each other leading to a self-patterning on the surface. We devised a unique layer-by-layer process for application of catalyst and inhibitor precursors on oxidized $\mathrm{Si}$ (100) surfaces before the ACCVD step to achieve a hierarchical arrangement. Patterning could be controlled by adjusting the molarity and application sequence of precursors. Contact angle measurements on these self-patterned surfaces indicated that manipulation of these hierarchical arrays resulted in a wide range of hydrophobic behavior changing from that of a sticky rose petal to a lotus leaf.

Inspired by the self-cleaning effect of lotus leaves, researchers have paid increasing attention to the generation of superhydrophobic surfaces having hierarchical structures with features ranging from micro- to nanoscale. The lotus leaf has a highly textured surface with protruding nubs $(20-40 \mu \mathrm{m})$ which are further covered with nanometre sized wax crystals. ${ }^{1}$ Lotus leaf-like surfaces can be created either by covering a rough surface with a low surface energy material or by roughening/ etching/patterning the surface of a hydrophobic material. Fabrication techniques of such surfaces include lithography, ${ }^{2}$ electrospinning, ${ }^{3}$ imprinting, ${ }^{4}$ plasma etching, ${ }^{5}$ wet chemical etching, ${ }^{6}$ sol-gel processing, ${ }^{7}$ multiple contact transfer, ${ }^{8}$ chemical vapor deposition (CVD) ${ }^{\mathbf{9}}$ and capillary forming technique. ${ }^{10,11}$

Functionalized vertically aligned multi-walled carbon nanotube (VA-MWCNT) arrays synthesized by CVD have also demonstrated superhydrophobic properties.,12 Moreover, combining the CVD technique with photolithography for generating patterned carbon nanotube (CNT) arrays on surfaces

${ }^{a}$ Department of Chemistry, Bilkent University, Bilkent, 06800 Ankara, Turkey. E-mail: bengu@fen.bilkent.edu.tr; Fax: +90 31226640 68; Tel: +903122902153

${ }^{b}$ Institute of Engineering and Science, Material Science and Nanotechnology Graduate Program, Bilkent University, Bilkent, 06800 Ankara, Turkey

$\dagger$ Electronic supplementary information (ESI) available: Fig. S1; AFM image of the $\mathrm{Co}-\mathrm{O}$ layer which was first dried at $40{ }^{\circ} \mathrm{C}$ and then oxidized at $200{ }^{\circ} \mathrm{C}$. Fig. S2; graph relative to the area of CNT islands for different catalyst configurations. Fig. S3; representative XPS spectra of (a) Si 2p, (b) Al 2p, (c) Fe 2p and (d) Co 2p for a reduced $\mathrm{Al} / \mathrm{Fe} / \mathrm{Al} / \mathrm{Co}(20 / 20 / 20 / 20)$ catalyst film (grey line in all figures shows the peak backgrounds and orange line shows the curve fitted). Contact angle movies, Video S1 and Video S2, of $\mathrm{Al} / \mathrm{Fe} / \mathrm{Al} / \mathrm{Co}$ samples 40/20/20/20 and 20/40/20/20, respectively. See DOI: 10.1039/c2nr30258f has also been shown to improve and tailor superhydrophobicity of these surfaces. ${ }^{13}$ However, additional steps such as patterning with lithography for creating complex structures to improve hydrophobic behavior or imparting self-cleaning properties are not often cost efficient. Therefore, a simple, one-step production technique is required for the generation of artificial lotus leaf-like surfaces.

Hence, the aim of this study is to imitate lotus leaf structures by creating dual-scale micro/nanostructures of aligned and patterned CNTs during the growth. For this purpose, we developed a unique technique based on the layer-by-layer application of catalyst and inhibitor precursors which is normally used to grow VA-MWCNTs by our group. ${ }^{14}$ By tuning the molarity, types, sequence and number of precursor and catalyst layers, we were able to not only generate hierarchical and patterned superhydrophobic VA-MWCNT arrays but also tailor the wettability properties. The resultant hierarchical structures were fully characterized (contact angle, surface topography, physical properties, and geometry) in order to identify the contribution of micro- and nano-structured aspects on water repellency. These hierarchical CNT arrays with micro- and nanoscales can be further developed to potentially find applications as self-cleaning dry-adhesives (gecko tapes), ${ }^{15}$ scaffolds for tissue growth ${ }^{16}$ and also hybrid nano-electronic structures. ${ }^{17}$

\section{Results and discussion}

Fig. 1 displays a simple flow schematic for the preparation of selfpatterned surfaces. In step 1, a $20 \mathrm{~nm}$ thick oxide layer was grown on a $\mathrm{Si}$ (100) surface through dry oxidation at $900{ }^{\circ} \mathrm{C}$ for 30 minutes. In step $2 \mathrm{a}$, aluminium nitrate $\left(\mathrm{Al}\left(\mathrm{NO}_{3}\right)_{3} \cdot 9 \mathrm{H}_{2} \mathrm{O}\right)$ solution was applied on the $\mathrm{Si} / \mathrm{SiO}_{2}$ surface and then treated at 


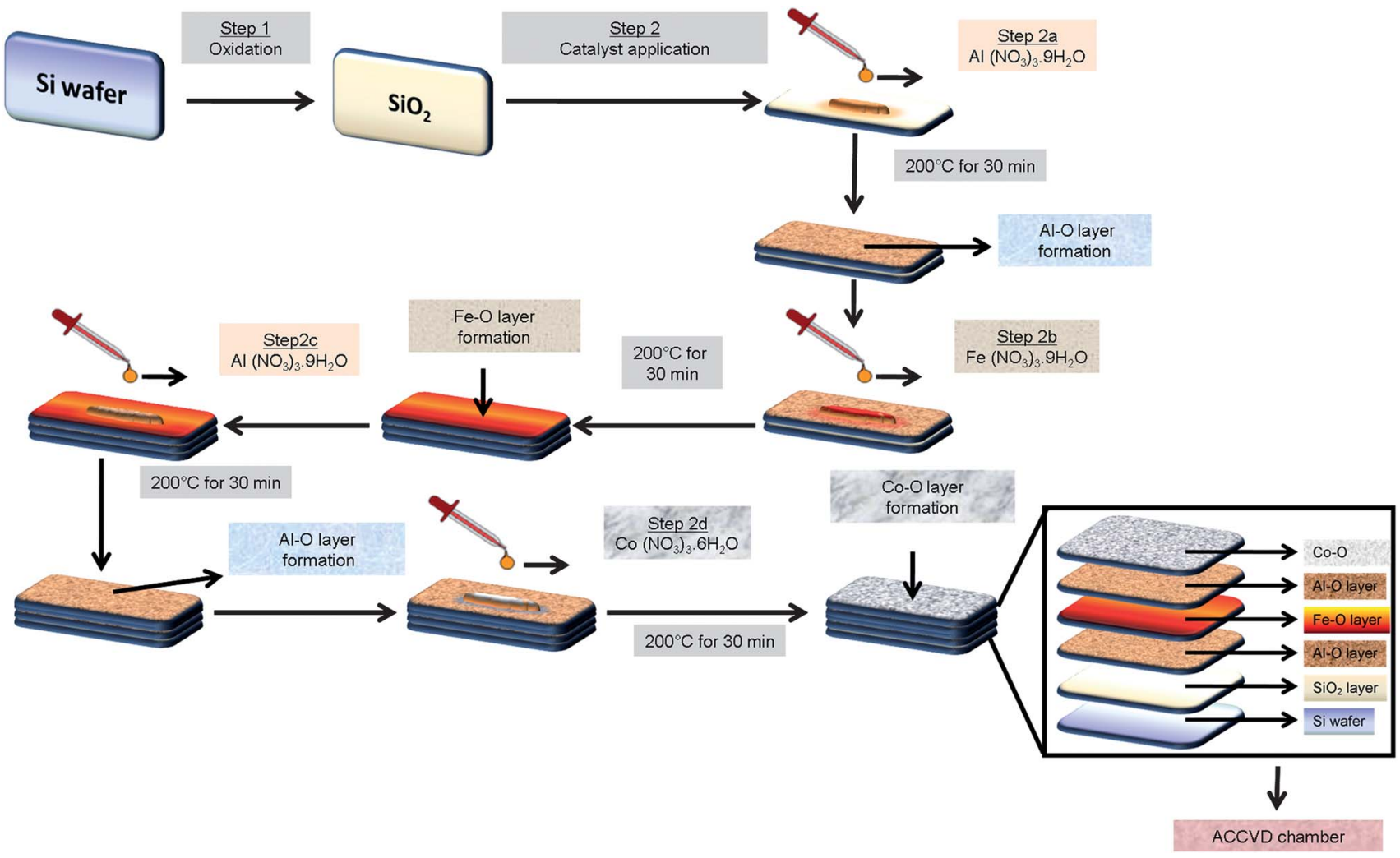

Fig. 1 Schematic representation of the layer-by-layer application of precursor and inhibitor precursors used for the preparation of self-patterned VAMWCNT arrays on Si surfaces. (The amount of catalyst and inhibitor solutions used was $20 \mu \mathrm{L} \mathrm{cm}^{-2}$ for each layer, unless stated otherwise.)

$200{ }^{\circ} \mathrm{C}$ which causes the formation of a thin aluminium oxide layer (Al-O) on the surface. With the help of atomic force microscopy (AFM), the thicknesses of the Al-O layer and other oxide layers were confirmed to be approximately $10 \mathrm{~nm}$ (ESI, Fig. $\mathrm{S} 1 \dagger$ ). The purpose of the Al-O layer (inhibitor) is to inhibit the diffusion of the catalyst metal to the substrate and also to prevent the agglomeration/ripening of the catalyst particles at high processing temperatures during alcohol catalyzed chemical vapor deposition (ACCVD). In step 2b, iron nitrate $\left(\mathrm{Fe}\left(\mathrm{NO}_{3}\right)_{3} \cdot 9 \mathrm{H}_{2} \mathrm{O}\right)$ catalyst solution was applied on the inhibitor layer and likewise treated at $200{ }^{\circ} \mathrm{C}$. At the end of step $2 \mathrm{~b}$, an $\mathrm{Al}-$ $\mathrm{O} / \mathrm{Fe}-\mathrm{O}(20 / 20)+$ bilayer has been formed on the surface of oxidized Si (100). At this point in the layer-by-layer flow, we employed X-ray photoelectron spectroscopy (XPS) to identify the chemical state of $\mathrm{Al}$ and Fe over Si (100) surfaces. XPS spectra of $\mathrm{Al} 2 \mathrm{p}, \mathrm{O} 1 \mathrm{~s}$ and $\mathrm{Fe} 2 \mathrm{p}$ regions for the $\mathrm{Al}-\mathrm{O} / \mathrm{Fe}-\mathrm{O}$ bilayer catalyst film are shown in Fig. 2. The binding energy position for the $\mathrm{Al} 2 \mathrm{p}$ peak $(73.7 \mathrm{eV})$ corresponds to the oxide state for $\mathrm{Al}-\mathrm{O} .{ }^{18}$ The deconvolution of $\mathrm{Fe} 2 \mathrm{p}^{3 / 2}$ shows peaks at $708.8 \mathrm{eV}$ and $713.8 \mathrm{eV}$ which correspond to $\mathrm{Fe}-\mathrm{O}$ and its satellite, respectively. ${ }^{19}$ As shown in Fig. 2, the $\mathrm{O}$ 1s spectra are

\.Hereon, we will be defining samples with the catalyst/inhibitor layer solution dosages $\left(\mu \mathrm{L} \mathrm{cm}^{-2}\right)$ applied with their respective turns, e.g. "Al-O/Fe-O (20/20)" indicates a sample where first a $20 \mu \mathrm{L} \mathrm{cm}{ }^{-2}$ dose of $\mathrm{Al}\left(\mathrm{NO}_{3}\right)_{3} \cdot 9 \mathrm{H}_{2} \mathrm{O}$ solution $\left(5 \mathrm{mmol} \mathrm{L} \mathrm{L}^{-1}\right)$ was applied, and followed with the application of another $20 \mu \mathrm{L} \mathrm{cm}$-2 dose of $\mathrm{Fe}\left(\mathrm{NO}_{3}\right)_{3} \cdot 9 \mathrm{H}_{2} \mathrm{O}$ solution $\left(5 \mathrm{mmol} \mathrm{L}^{-1}\right)$. Samples after the ACCVD process were named just with the metallic states throughout the manuscript, e.g. $\mathrm{Al} / \mathrm{Fe}$ $(20 / 20)$.
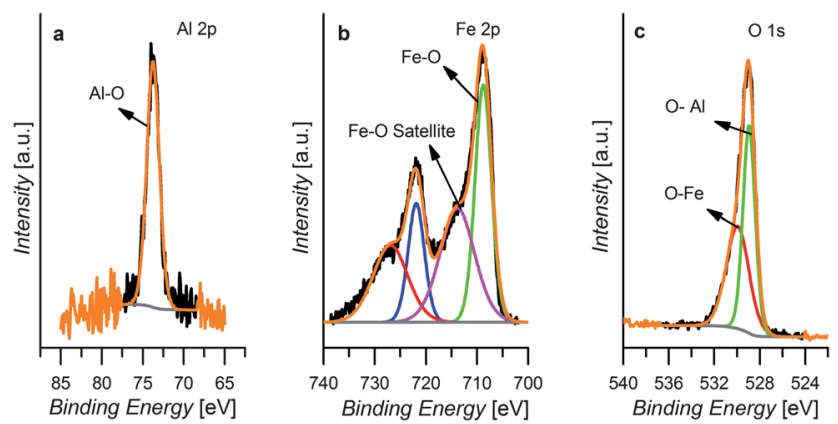

Fig. 2 Representative XPS spectra of (a) Al 2p (b) Fe 2p and (c) O 1s for $\mathrm{Al}-\mathrm{O} / \mathrm{Fe}-\mathrm{O}$ bilayer catalyst films over $\mathrm{Si}(100)$ surfaces prior to the CNT synthesis step. The grey line in all figures shows the peak backgrounds and the orange line shows the curve fitted.

deconvoluted into two peaks at $528.9 \mathrm{eV}$ and $529.9 \mathrm{eV}$ which correspond to $\mathrm{Al}-\mathrm{O}^{20}$ and $\mathrm{Fe}-\mathrm{O},{ }^{21}$ respectively. After the XPS analysis, the $\mathrm{Al}-\mathrm{O} / \mathrm{Fe}-\mathrm{O}(20 / 20)$ sample was loaded into the furnace for the ACCVD process. During the scanning electron microscopy (SEM) analysis after the ACCVD, we observed poorly aligned and non-uniformly distributed patches of CNTs on the surface of the $\mathrm{Al} / \mathrm{Fe}(20 / 20)$ sample (Fig. 3a).

Motivated by an earlier study of Cantoro et $a .^{22}$ indicating significant improvement in the coverage, alignment and density of vertically aligned CNTs grown from a catalyst layer sandwiched between two Al layers, we have modified our solution based layer-by-layer catalyst application method with the 

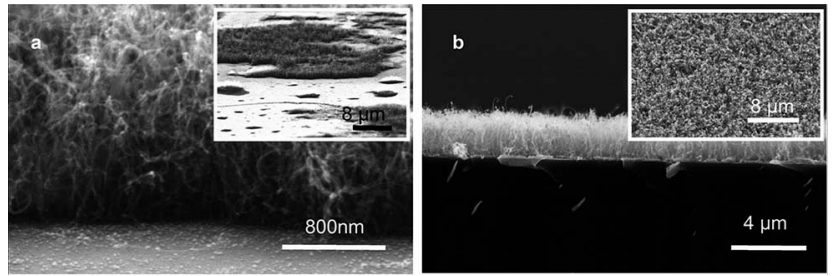

Fig. 3 SEM images of CNT arrays grown on (a) Al/Fe (20/20) and (b) $\mathrm{Al} / \mathrm{Fe} / \mathrm{Al}(20 / 20 / 20)$ catalyst configurations. Insets show $45^{\circ}$ tilted SEM images.

addition of a second $\mathrm{Al}-\mathrm{O}$ layer following the $\mathrm{Fe}-\mathrm{O}$ layer, namely step $2 c$ in Fig. 1 (Al-O/Fe-O/Al-O (20/20/20)). Fig. 3b shows the side and top view SEM images of a sample loaded into the furnace for ACCVD after the completion of step 2c, indicating good coverage and well-alignment of CNTs.

In our other studies using e-beam evaporation for the catalyst layers, we observed that VA-MWCNTs synthesized using a Co catalyst were significantly taller and denser than those grown from a Fe catalyst under the same conditions, as shown in Fig. 4a and $b$. A survey of the literature on the comparative performance of $\mathrm{Fe}$ and Co catalysts reveals that the activity of the catalyst layer strongly depends on the carbon source. Hence, it is reported that $\mathrm{Co}$ is more active with alcohol based sources while Fe shows higher activity with hydrocarbon sources such as ethylene ${ }^{23}$ or methane. ${ }^{24}$ Therefore, in order to manufacture multi-level hierarchical VA-MWCNTs we decided to incorporate another step (step 2d) involving the application of a cobalt nitrate $(\mathrm{Co}(\mathrm{N}-$ $\left.\mathrm{O}_{3}\right)_{2} \cdot 6 \mathrm{H}_{2} \mathrm{O}$ ) catalyst solution in our layer-by-layer procedure. Thus, at the end of step $2 \mathrm{~d}$, the sample had an $\mathrm{Al}-\mathrm{O} / \mathrm{Fe}-\mathrm{O} / \mathrm{Al}-\mathrm{O} /$ Co-O (20/20/20/20) catalyst-inhibitor multilayer configuration. Fig. 5a shows SEM images of VA-MWCNTs grown on a sample loaded into the furnace after step $2 \mathrm{~d}$. It is easily observed that adding the Co layer resulted in the arrangement of a dual-scale hierarchical pattern formed by randomly scattered patches of tall CNT arrays $(\sim 10 \mu \mathrm{m})$ towering over the underlying shorter CNT $(\sim 2 \mu \mathrm{m})$ background. These patterns of dual-scale CNT arrays have a surface structure similar to that of a natural lotus leaf.

We employed Raman and transmission electron microscopy (TEM) techniques in order to address the type of our CNTs. The Raman spectrum (Fig. 6a) of the patterned CNT arrays shows G (tangential mode) and D (disorder mode) bands at $1584 \mathrm{~cm}^{-1}$ and $1347 \mathrm{~cm}^{-1}$, respectively, which indicates the presence of multiwalled CNTs. Moreover, low- and high-resolution TEM images (Fig. 6b and inset, respectively) confirm CNTs to be of the multiwalled variety.
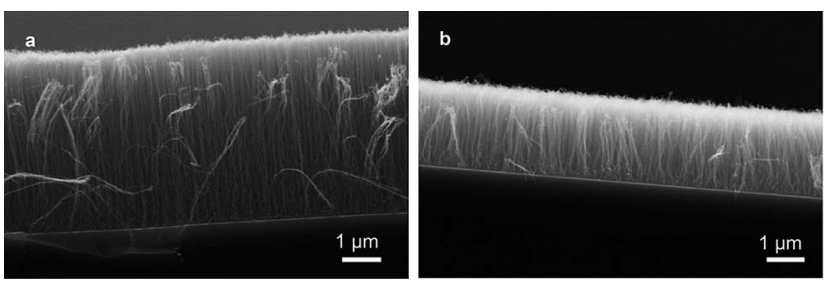

Fig. 4 Cross-sectional SEM images of VA-MWCNTs synthesized using (a) Co and (b) Fe catalysts deposited using e-beam evaporation.
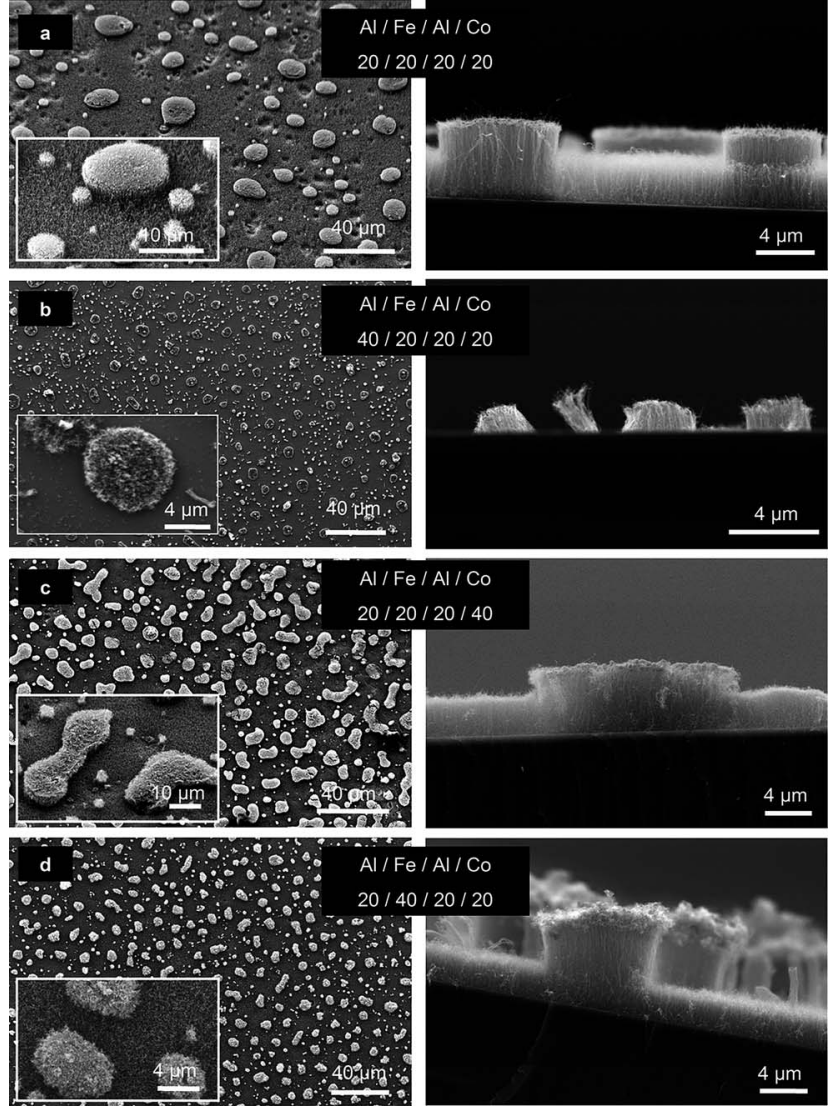

Fig. 5 SEM images of VA-MWCNT arrays grown on different multilayer catalyst configurations of $\mathrm{Al} / \mathrm{Fe} / \mathrm{Al} / \mathrm{Co}$ : (a) 20/20/20/20, (b) 40/20/ $20 / 20$, (c) 20/20/20/40 and (d) 204/40/20/20. The insets in all figures are high magnified SEM images and the labels show the catalyst configuration and the amount of catalyst/inhibitor solutions in $\mu \mathrm{L} \mathrm{cm}^{-2}$.

In order to better understand the root cause for the height differences of CNT patches, we analyzed the $\mathrm{Al}-\mathrm{O} / \mathrm{Fe}-\mathrm{O} / \mathrm{Al}-\mathrm{O}$ surface using energy dispersive spectroscopy (EDS) mapping under SEM investigation after the drying of $\mathrm{Co}\left(\mathrm{NO}_{3}\right)_{2} \cdot 6 \mathrm{H}_{2} \mathrm{O}$ catalyst solution at $40{ }^{\circ} \mathrm{C}$ and following the calcination step at $200{ }^{\circ} \mathrm{C}$. The corresponding data are given in Fig. $7 \mathrm{a}$ and b, respectively. An EDS generated elemental map of the dried $\mathrm{Co}\left(\mathrm{NO}_{3}\right)_{2} \cdot 6 \mathrm{H}_{2} \mathrm{O}$ layer on $\mathrm{Al}-\mathrm{O} / \mathrm{Fe}-\mathrm{O} / \mathrm{Al}-\mathrm{O}$ shows that Co rich patches were present (Fig. 7a). Again, Co-rich patches were also observed on the surface after the calcination process at $200{ }^{\circ} \mathrm{C}$ (Fig. 7b). EDS data clearly show the formation of Co-rich patches during the drying step, while Fe gets dispersed uniformly across the whole surface. After the ACCVD process, we observed that taller CNT patches (average area of $73 \mu \mathrm{m}^{2}$, ESI, Fig. S2 $\dagger$ ) were formed on Co-rich regions on the surface and the underlying shorter CNT arrays were on Fe rich areas.

According to the literature available, the observation of micrometre sized Co-rich islands could also be related to the dispersion of $\mathrm{Co}$ on the $\mathrm{Al}-\mathrm{O}$ inhibitor layer. Zhang et al. ${ }^{25}$ reported on the dispersion capacities of $\mathrm{CoO} / \gamma-\mathrm{Al}_{2} \mathrm{O}_{3}$ and $\mathrm{Co}_{3} \mathrm{O}_{4} / \gamma-\mathrm{Al}_{2} \mathrm{O}_{3}$ layers obtained from cobalt acetate and $\mathrm{Co}\left(\mathrm{NO}_{3}\right)_{2} \cdot 6 \mathrm{H}_{2} \mathrm{O}$ precursors, $0.015 \mathrm{mmol} \mathrm{\textrm {m } ^ { - 2 }}$ and $0.0015 \mathrm{mmol} \mathrm{m}^{-2}$, respectively. Beyond the reported capacity, in the $\mathrm{Co}_{3} \mathrm{O}_{4} / \gamma-\mathrm{Al}_{2} \mathrm{O}_{3}$ system $\mathrm{Co}-\mathrm{O}$ islands were reported to 

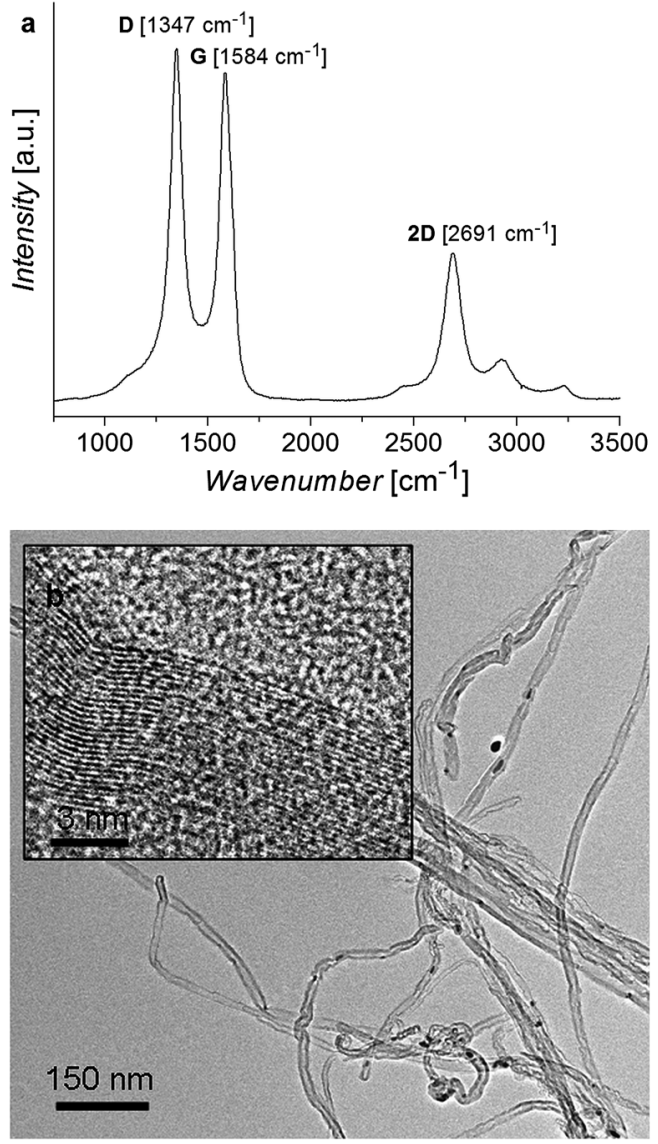

Fig. 6 (a) Raman spectrum and (b) low- and high-resolution (inset) TEM images of multi-walled CNTs.

agglomerate. In this study, the Co concentration on the Al-O inhibitor layer was $1.0 \mathrm{mmol} \mathrm{m} \mathrm{m}^{-2}$ which is higher than the reported values. For the investigation of the oxidation state of Co after step $2 \mathrm{~d}$ in the procedure, FT-IR analysis was employed. As shown in Fig. 8, we found that the FT-IR spectrum was dominated by two peaks located at $667 \mathrm{~cm}^{-1}$ and $561 \mathrm{~cm}^{-1}$ corresponding to those reported for $\mathrm{Co}_{3} \mathrm{O}_{4}$ spinel formation. ${ }^{25}$ Another study related to limited Co mobility was reported by Murakami et al. ${ }^{26}$ for bimetallic catalysts. In this report, $\mathrm{Fe}-\mathrm{Si}$ compound barrier layer formation due to preferential $\mathrm{Fe}$ diffusion into the $\mathrm{SiO}_{2}$ layer limited the mobility of Co islands on the surface. Overall, the final hierarchical VA-MWCNT formation observed on the surface is believed to be due to the agglomeration of nanometre sized Co particles into micrometre sized islands and also the activity difference between $\mathrm{Fe}$ and $\mathrm{Co}$ under the conditions used for ACCVD in this study. Fig. 9 shows our proposed VA-MWCNT growth mechanism where the taller CNT arrays were grown on Co-rich regions while the shorter CNTs were grown on Fe rich areas. Moreover, XPS analysis on the Al-O/Fe-O/Al-O/Co-O (20/20/20/20) sample subjected to the reduction step shows the presence of $\mathrm{Fe}$ and $\mathrm{Co}$ on the surface at the same time just before the onset of CNT growth (ESI, Fig. S3†).

The effect of Al-O inhibitor layer on the dual-scale patterning was investigated by varying the amount of $\mathrm{Al}\left(\mathrm{NO}_{3}\right)_{3} \cdot 9 \mathrm{H}_{2} \mathrm{O}$ inhibitor solution from $20 \mu \mathrm{L}$ to $40 \mu \mathrm{L}$ for the first layer in the
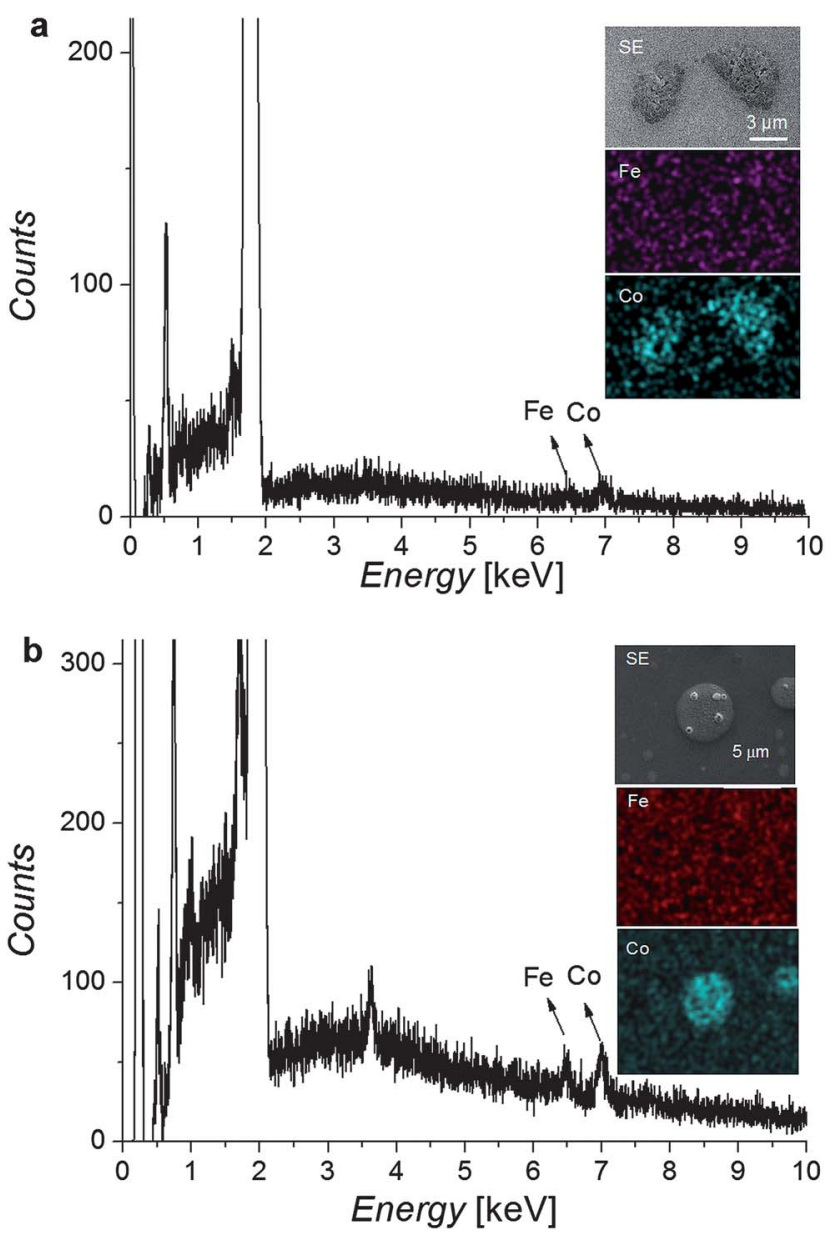

Fig. 7 EDS spectra from the $\mathrm{Al}-\mathrm{O} / \mathrm{Fe}-\mathrm{O} / \mathrm{Al}-\mathrm{O}$ surface (a) after the drying of $\mathrm{Co}\left(\mathrm{NO}_{3}\right)_{2} \cdot 6 \mathrm{H}_{2} \mathrm{O}$ at $40{ }^{\circ} \mathrm{C}$ and (b) after the calcination step at $200{ }^{\circ} \mathrm{C}$ prior to ACCVD. Insets show the pseudo-colored elemental mapping for $\mathrm{Fe}, \mathrm{Co}$ and the corresponding secondary electron image (SE).

layer-by-layer approach (40/20/20/20) (Fig. 5b). Compared to the Al/Fe/Al/Co (20/20/20/20) sample, smaller CNT patches (average area of $\left.11 \mu \mathrm{m}^{2}\right)$ were obtained for the Al/Fe/Al/Co (40/20/20/20) multilayer catalyst configuration. EDS mapping on the $\mathrm{Al}-\mathrm{O} / \mathrm{Fe}-\mathrm{O} / \mathrm{Al}-\mathrm{O} / \mathrm{Co}-\mathrm{O}(40 / 20 / 20 / 20)$ sample also shows that islands were Co-rich where CNTs were only grown on this catalyst. It is observed that an increased amount of inhibitor precursor drowns the Fe layer and thus completely hinders the shorter CNT array formation as observed in Fig. 5b. In the literature, an indirect effect of $\mathrm{Al}$ layer on the CNT growth rate has been discussed. It was reported that the thickness of the Al layer could be responsible for controlling the length of CNTs. ${ }^{27-30}$ The impact was mainly attributed to the diffusion of $\mathrm{Al}$ into the catalyst layer leading to a decrease in the carbon solubility in the catalyst particles. As shown in the literature, the decrease in the carbon solubility resulted in shorter CNTs as the Al layer thickness increases. However, we believe that the Al layer thickness could be a minor factor in how much Al is diffusing into the catalyst islands, as the driving force for diffusion is not related to the amount of $\mathrm{Al}$ available, but rather to the gradient of the chemical potential of Al. Also, in our case, there is an $\mathrm{Al}$ 


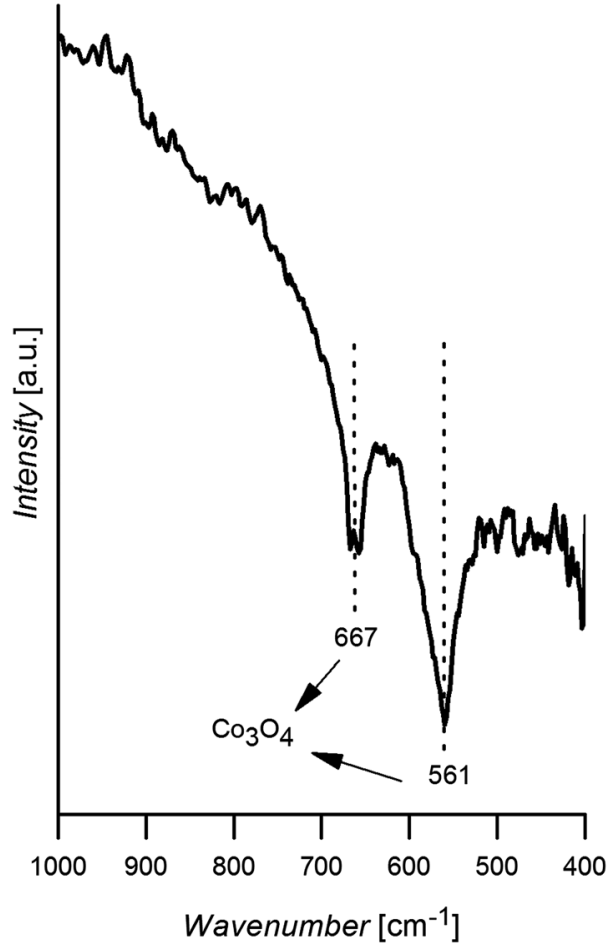

Fig. 8 FT-IR spectrum of $\mathrm{Al}-\mathrm{O} / \mathrm{Fe}-\mathrm{O} / \mathrm{Al}-\mathrm{O} / \mathrm{Co}-\mathrm{O}$ multilayer catalysts over $\mathrm{Si}(100)$ surfaces prior to the CNT synthesis step.

oxide layer, which is stable up to $800{ }^{\circ} \mathrm{C}$. Therefore, it is more likely for the Al-O layers to block the access of carbonaceous gas to Fe catalyst particles.

The amounts of catalyst precursor solutions were changed to examine their effects on the dual-scale patterning. First, we increased the $\mathrm{Co}\left(\mathrm{NO}_{3}\right)_{2} \cdot 6 \mathrm{H}_{2} \mathrm{O}$ catalyst solution amount from $20 \mu \mathrm{L}$ to $40 \mu \mathrm{L}(20 / 20 / 20 / 40)$ in step $2 \mathrm{c}$. The results are given in Fig. $5 c$, which clearly shows an increase for the average area of taller CNT patches from 73 to $177 \mu \mathrm{m}^{2}$, respectively. Then, we studied the role of $\mathrm{Fe}$ on dual-scale patterning in the same catalyst configuration $(\mathrm{Al}-\mathrm{O} / \mathrm{Fe}-\mathrm{O} / \mathrm{Al}-\mathrm{O} / \mathrm{Co}-\mathrm{O})$. It is observed that increasing the $\mathrm{Fe}\left(\mathrm{NO}_{3}\right)_{3} \cdot 9 \mathrm{H}_{2} \mathrm{O}$ catalyst solution amount from $20 \mu \mathrm{L}$ to $40 \mu \mathrm{L}$ gave rise to a high yield CNT formation on the bottom layer (20/40/20/20) (Fig. 5d). On the other hand, a decrease in the area of the tall CNT patches was recorded (average area of $20 \mu \mathrm{m}^{2}$ ) by the increase in the Fe catalyst amount.

We also investigated the wetting properties of VA-MWCNTs and self-patterned VA-MWCNTs. A water droplet on a rough hydrophobic surface can display two distinct states: the Wenzel state $^{31}$ in which the droplet makes intimate contact with the surface asperities and the Cassie-Baxter state ${ }^{32}$ in where the droplet sits on the top of the asperities. Superhydrophobic surfaces can be defined with the well-known Cassie-Baxter state. The main difference between Wenzel and Cassie states is the hysteresis contact angle value which can be defined as the difference between advancing $\left(\theta_{\mathrm{a}}\right)$ and receding contact angle $\left(\theta_{\mathrm{r}}\right) .^{33,34}$ Balu et al. ${ }^{35}$ classified superhydrophobicity into two categories depending on the contact angle hysteresis values: rolloff superhydrophobicity $\left(\theta_{\mathrm{a}}>150^{\circ}, \Delta \theta<10^{\circ}\right)$ and sticky superhydrophobicity $\left(\theta_{\mathrm{a}}>150^{\circ}, \Delta \theta>10^{\circ}\right)$. The advancing and

\section{Oxidized Layers (top view)}

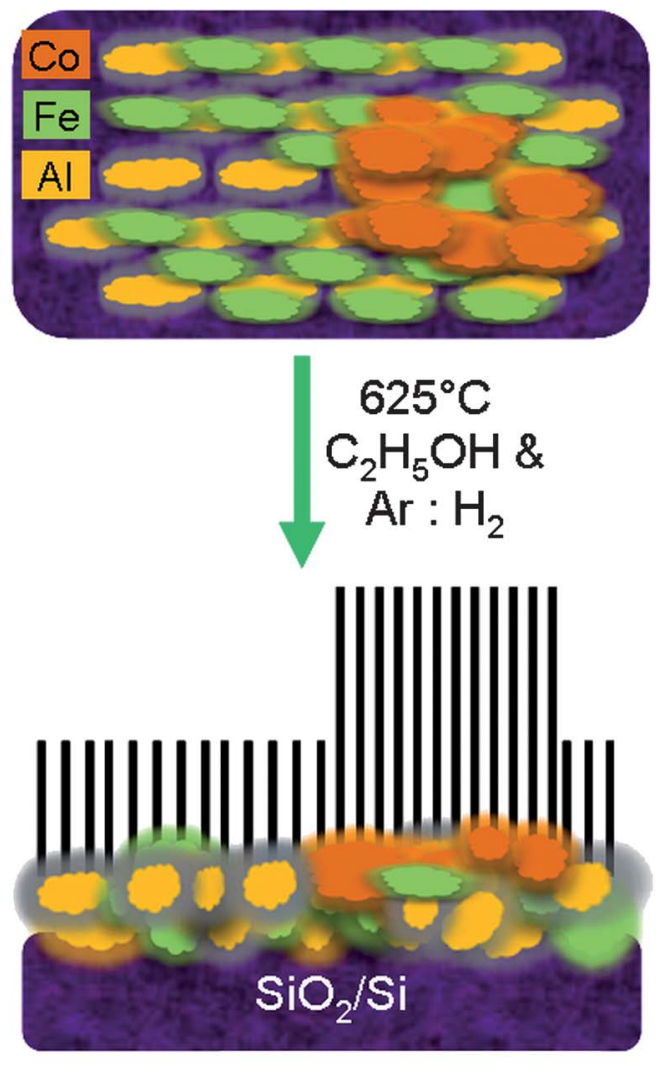

Dual-scale CNTs (side view)

Fig. 9 Schematic representation of the VA-MWCNT growth where the taller CNT arrays were grown on Co-rich regions while the shorter CNTs were grown on Fe rich areas.

receding water contact angles on the VA-MWCNTs grown on the $\mathrm{Al} / \mathrm{Fe} / \mathrm{Al}(20 / 20 / 20)$ multilayer catalyst configuration were measured as $145^{\circ}$ and $100^{\circ}$, respectively which indicate this surface to be a sticky Wenzel surface. Hence, it is observed that the droplet stuck to this surface and did not roll-off when the surface was tilted to $90^{\circ}$ (Fig. 10a) and even at $180^{\circ}$ (Fig. 10b). In contrast, dual-scale self-patterned surfaces synthesized with the $\mathrm{Al} / \mathrm{Fe} / \mathrm{Al} / \mathrm{Co}$ (20/20/20/20) catalyst configuration exhibited superhydrophobic behavior (Fig. 10c). The advancing angle measured on this dual-scale patterned surface was $158^{\circ}$ while the receding angle was $149^{\circ}$. Hence, introducing a dual-scaled roughness with micro- and nano-sized structures generated a superhydrophobic surface where the penetration of the droplet between the asperities was not possible. Dual-scale VA-MWCNTs were again observed when the amount of Co increased in the $\mathrm{Al} / \mathrm{Fe} / \mathrm{Al} / \mathrm{Co}(20 / 20 / 20 / 40)$ catalyst configuration. These densely packed CNT patches with a larger diameter displayed a contact angle hysteresis of $13^{\circ}$ and also the advanced contact angle was measured to be $151^{\circ}$ less than that of the 20/20/ 20/20 sample with smaller islands (Fig. 10d). On the other hand, an ultimate non-wetting state was observed on the samples with increased $\mathrm{Al}$ and $\mathrm{Fe}$ amounts in different $\mathrm{Al} / \mathrm{Fe} / \mathrm{Al} / \mathrm{Co}$ (40/20/20/ 20 and 20/40/20/20, respectively) catalyst configurations (see Video $\mathrm{S} 1$ and Video $\mathrm{S} 2 \dagger$, respectively). In other words, one-level 

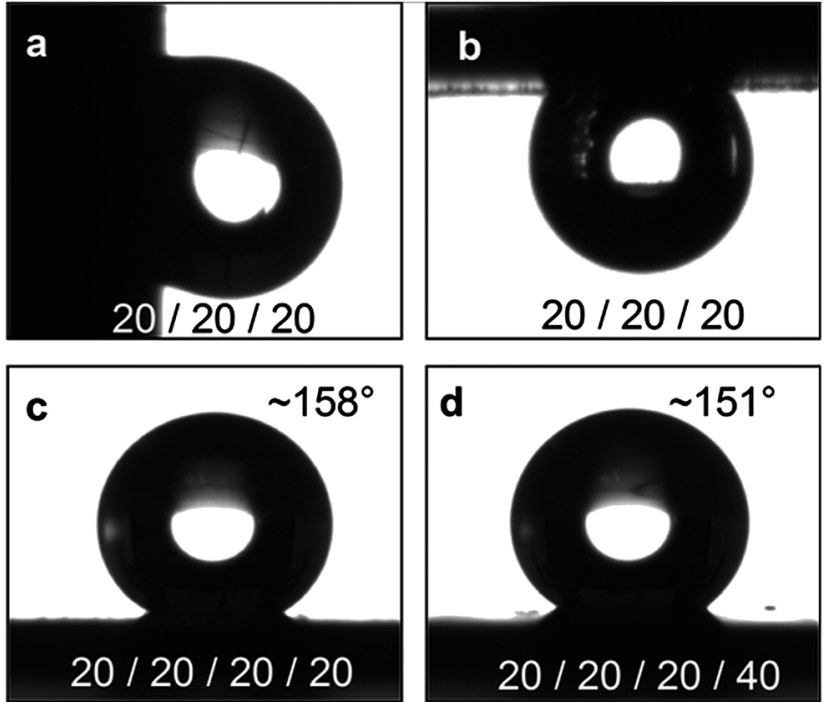

Fig. 10 (a) $90^{\circ}$ tilted and (b) $180^{\circ}$ tilted optical images of water droplets on VA-MWCNTs grown on $\mathrm{Al} / \mathrm{Fe} / \mathrm{Al}(20 / 20 / 20)$. Contact angles on the self-patterned CNTs grown on (c) Al/Fe/Al/Co (20/20/20/20) and (d) Al/ $\mathrm{Fe} / \mathrm{Al} / \mathrm{Co}(20 / 20 / 20 / 40)$ multilayer catalyst configuration.

CNT islands and dual-scale patterns with very small CNT patches having an average area less than $20 \mu \mathrm{m}^{2}$ strongly repelled the suspending water droplet. Pulling the suspending water droplet onto the structured surfaces was found to be nearly impossible even after pushing the droplet multiple times against the surface. Attempts with various droplet volumes ranging from 2 to $10 \mu \mathrm{L}$ were performed, only to observe that droplets just rolled off the sample surface instantaneously without following a specific direction. This observed behavior was akin to a Leidenfrost drop for which the underlying vapor minimizes the friction. In this case, the solid-liquid contact vanishes and the liquid cannot be pinned anymore on the solid defects, which also yields a zero contact angle hysteresis. ${ }^{36}$ In Table 1, a summary of the catalyst layer configurations, the resultant morphology and patterning of VA-MWCNTs and their wettability properties are given.

\section{Conclusions}

In this study, hierarchical structures ranging from micro- to nano-scale found in artificial lotus leaf surfaces were successfully mimicked by a one-step process developed from VA-MWCNT arrays. This process allowed for the synthesis of "tall" and "short" CNT arrays simultaneously, thus creating dual-scale CNT coverage on a surface. Through controlling the process parameters, the height of the "tall" CNT patches could be tuned and moreover areas without CNT coverage could be achieved on demand. Catalyst type, amount and application sequence were found to be major parameters in defining the final pattern of these hierarchical VA-MWCNT arrays. Further analysis showed that the degree of water repellency of these surfaces was strongly influenced by the final surface patterning. Some of these hierarchical self-patterned VA-MWCNT arrays exhibited superhydrophobic behavior, while others exhibited a behavior similar to a Leidenfrost drop. The major advantage of the technique

Table 1 Schematic representation and aspect ratio of patterns on the surfaces having different catalyst configurations

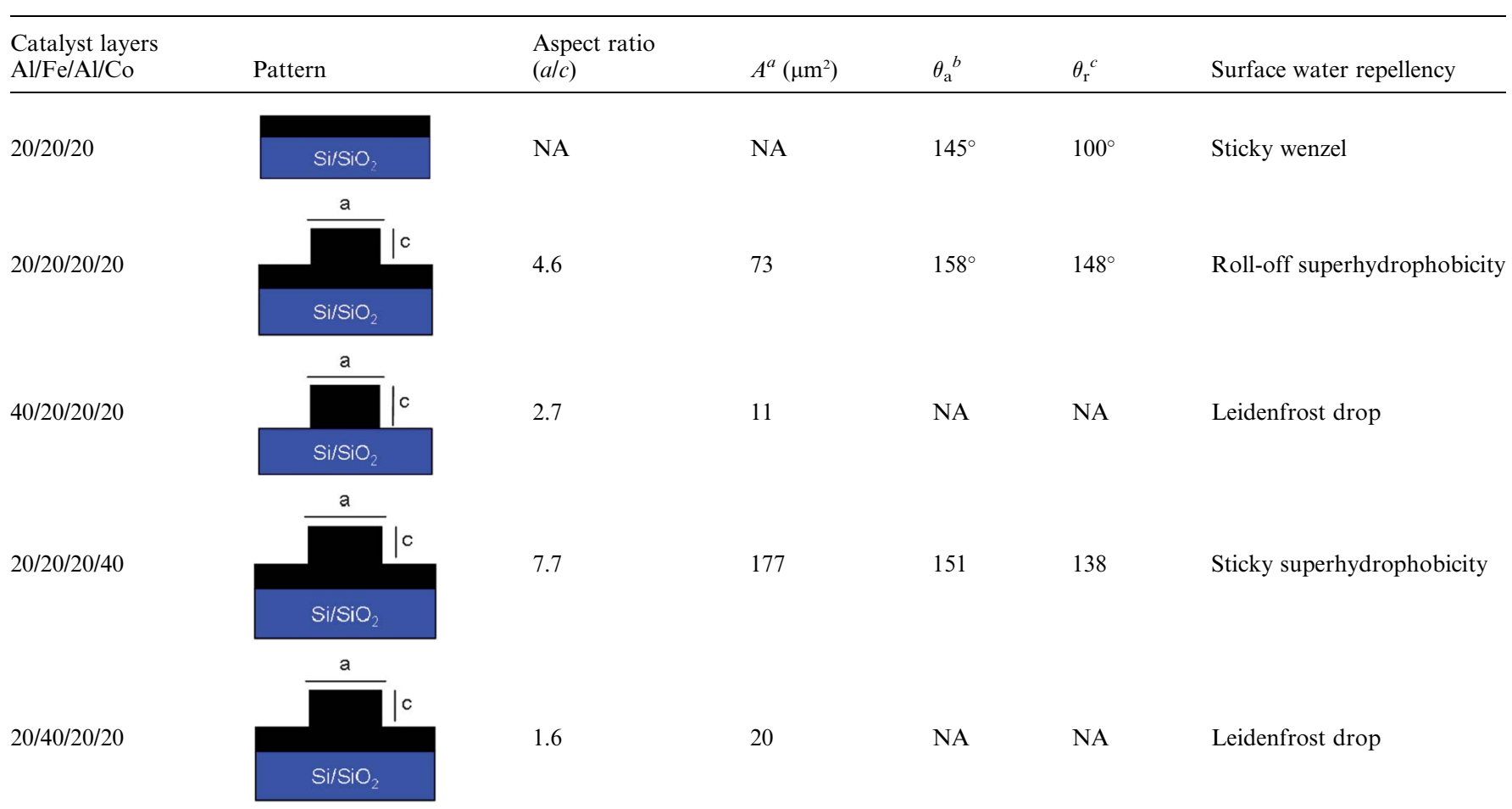

${ }^{a}$ Average area of CNT patches $\left(\lambda \mathrm{m}^{2}\right) .{ }^{b}$ Advancing angle of water on the CNT surfaces. ${ }^{c}$ Receding angle of water on the CNT surfaces. 
developed in this study is that it is a one-step process and it does not require "pre-patterning" steps such as lithography, etc.

\section{Methods}

Self-patterned VA-MWCNT arrays were grown by the ACCVD process. ${ }^{14}$ A solution based layer-by-layer method was used for the application of catalyst and inhibitor layers. Inhibitor and catalyst solutions were prepared individually by dissolving $\mathrm{Al}\left(\mathrm{NO}_{3}\right)_{3} \cdot 9 \mathrm{H}_{2} \mathrm{O}$ (Sigma-Aldrich, ACS reagent $\geq 98 \%$ ), $\mathrm{Co}\left(\mathrm{NO}_{3}\right)_{2} \cdot 6 \mathrm{H}_{2} \mathrm{O}$ (Sigma-Aldrich, ACS reagent $\geq 98 \%$ ) or $\mathrm{Fe}\left(\mathrm{NO}_{3}\right)_{3} \cdot 9 \mathrm{H}_{2} \mathrm{O}$ (Sigma-Aldrich, ACS reagent $\geq 98 \%$ ) powders in the corresponding amount of pure ethanol (Sigma-Aldrich, $\mathrm{CH}_{3} \mathrm{CH}_{2} \mathrm{OH}, \geq 99.8 \%$, GC). The concentrations of nitrate solutions were adjusted to be between 1 and $10 \mathrm{mM}$ for each metal-based precursor. Before the application of nitrate solutions, oxidized Si (100) wafers were ultrasonically cleaned in a peroxide-water mixture $(50: 50)$ for 30 minutes. Catalyst and inhibitor solutions were applied layer-by-layer on $\mathrm{SiO}_{2} / \mathrm{Si}$ wafer $\left(1 \times 1 \mathrm{~cm}^{2}\right)$ by using a micropipette. The cleaned $\mathrm{Si}(100)$ wafer was placed on a hot plate adjusted to $40{ }^{\circ} \mathrm{C}$. Then, the inhibitor layer precursor $\left(\mathrm{Al}\left(\mathrm{NO}_{3}\right)_{3} \cdot 9 \mathrm{H}_{2} \mathrm{O}\right)$ was applied and left for drying in air for about a minute at this temperature. Following this step, the wafer with the dried $\mathrm{Al}$ inhibitor layer was calcinated in air at $200{ }^{\circ} \mathrm{C}$ for 30 minutes. On the $\mathrm{Al}-\mathrm{O}$ inhibitor layer, a Fe catalyst precursor $\left(\mathrm{Fe}\left(\mathrm{NO}_{3}\right)_{3} \cdot 9 \mathrm{H}_{2} \mathrm{O}\right)$ was applied in the same manner, and also subjected to the same procedure used for preparing the Al-O layer. The following Al- $\mathrm{O}, \mathrm{Fe}-\mathrm{O}$ and/or $\mathrm{Co}-\mathrm{O}$ layers were prepared exactly following the steps detailed above. A schematic representation of the step-wise application of precursors in a layer-by-layer manner is shown in Fig. 1. In a second set of experiments, we used e-beam and thermal deposition techniques for the application of $\mathrm{Fe}$ and Co catalysts on $\mathrm{Si}$ (100) wafers. First, a $10 \mathrm{~nm} \mathrm{Al} \mathrm{layer} \mathrm{was} \mathrm{deposited} \mathrm{as} \mathrm{the} \mathrm{inhibitor} \mathrm{layer} \mathrm{via}$ a thermal evaporation technique. Afterwards, a $1 \mathrm{~nm}$ thick Fe or Co catalyst layer was deposited using an e-beam evaporator on the Al/Si wafer. Subsequently, the samples prepared by evaporation or by the calcination of nitrate based solutions were introduced into a vacuum capable ACCVD furnace via a load lock. The reduction step proceeded under $\mathrm{H}_{2}$ and $\mathrm{Ar}$ atmospheres (flow rates $20 \mathrm{sccm}$ and $150 \mathrm{sccm}$, respectively) at $625^{\circ} \mathrm{C}$ for $15 \mathrm{~min}$. Following this step, CNT growth was performed by diverting the $\mathrm{Ar}: \mathrm{H}_{2}(5: 1)$ gas mixture through a bubbler filled with pure ethanol for $30 \mathrm{~min}$.

\section{Characterization}

SEM imaging and EDS analysis of the self-patterned VAMWCNTs were performed on a Carl-Zeiss EVO 40 ( $\mathrm{LaB}_{6}$ filament) while TEM imaging was done using a JEOL (JEM-2100 F) microscope operating at $200 \mathrm{kV}$. XPS spectra were recorded on a custom Specs XPS system (Hemispherical Energy Analyzer PHOIBOS 100/150). Monochromated AlK $\alpha(E=1486.6 \mathrm{eV})$ emission was used as the X-ray source. The pressure of the analysis chamber was kept at $10^{-10}$ mbar. Survey XPS spectra and narrow scan XPS spectra were collected with pass energies of $50 \mathrm{eV}$ and $20 \mathrm{eV}$, respectively. The Raman spectrum was recorded with a Horiba (Jobin-Yvon MicroRaman-532 nm wavelength) spectrometer. AFM images were recorded in tapping mode by using a NanoMagnetics AFM instrument. FT-IR spectra were collected on a Tensor 27 FT-IR spectrometer, working in the range of wavenumbers $400-4000 \mathrm{~cm}^{-1}$ at a resolution of $4 \mathrm{~cm}^{-1}$ (number of scans, 32). Contact angle measurements were performed on a dynamic contact angle measurement instrument (Dataphysics OCA 15 plus). Contact angle values reported in the present study represent the average from six consecutive measurements.

\section{Acknowledgements}

E. D. Sam and G. Kucukayan-Dogu thank the Scientific and Technological Research Council of Turkey (Tubitak) for financial support. The authors are grateful to Huseyin Alagoz and Mustafa Fatih Genisel for their help. This work was partially supported by Tubitak Projects 109T026 and 107T892.

\section{References and notes}

1 W. Barthlott and C. Neinhuis, Planta, 1997, 202, 1-8.

2 R. A. Singh, E. S. Yoon, H. J. Kim, H. Kong, S. Park, H. E. Jeong and K. Y. Suh, Surf. Eng., 2007, 23, 161-164.

3 K. Acatay, E. Simsek, C. Ow-Yang and Y. Z. Menceloglu, Angew. Chem., Int. Ed., 2004, 43, 5210-5213.

4 B. Liu, Y. He, Y. Fan and X. Wang, Macromol. Rapid Commun., 2006, 27, 1859-1864.

5 S. R. Coulson, I. Woodward, J. P. S. Badyal, S. A. Brewer and C. Willis, J. Phys. Chem. B, 2000, 104, 8836-8840.

6 B. T. Quian and Z. Q. Shen, Langmuir, 2005, 21, 9007-9009.

7 H. M. Shang, Y. Wang, S. J. Limmer, T. P. Chou, K. Takahashi and G. Z. Cao, Thin Solid Films, 2005, 472, 37-43.

8 L. Qu, R. A. Vaia and L. Dai, ACS Nano, 2011, 5, 994-1002.

9 L. Huang, S. P. Lau, H. Y. Yang, E. S. P. Leong, S. F. Yu and S. Prawer, J. Phys. Chem. B, 2005, 109, 7746-7748.

10 M. De Volder, S. H. Tawfick, S. J. Park, D. Copic, Z. Zhao, W. Lu and A. J. Hart, Adv. Mater., 2010, 22, 4384-4389.

11 D. N. Futaba, K. Hata, T. Yamada, T. Hiraoka, Y. Hayamizu, Y. Kakudate, O. Tanaike, H. Hatori, M. Yumura and S. Iijima, Nat. Mater., 2006, 5, 987-994.

12 K. K. S. Lau, J. Bico, K. B. K. Teo, M. Chhowalla, G. A. J. Amaratunga, W. I. Milne, G. H. Mckinley and K. K. Gleason, Nano Lett., 2003, 3, 1701-1705.

13 L. Zhu, Y. Xiu, J. Xu, P. A. Tamirisa, D. W. Hess and C. P. Wong, Langmuir, 2005, 21, 11208-11212.

14 B. Baykal, V. Ibrahimova, G. Er, E. Bengu and D. Tuncel, Chem. Commun., 2010, 46, 6762-6764.

15 S. Sethi, L. Ge, L. Ci, P. M. Ajayan and A. Dhinojwala, Nano Lett., 2008, 8, 822-825.

16 A. Abarrategi, M. C. Gutierrez, C. Moreno-Vicente, M. J. Hortigüela, V. Ramos, J. L. Lopez-Lacomba, M. L. Ferrer and F. del Monte, Biomaterials, 2008, 29, 94-102.

17 K. Rana, G. Kucukayan-Dogu and E. Bengu, Appl. Surf. Sci., 2012, 258, 7112-7117.

18 J. F. Moulder, W. F. Stickle, E. P. Sobel and K. D. Bomben, Handbook of X-Ray Photoelectron Spectroscopy, ed. J. Chastian Perkin Elmer, Minnesota, 1992.

19 B. Heinrich, A. Demund and R. Szargan, Phys. Status Solidi C, 2007, 4, 1836-1843.

20 N. H. Turner and A. M. Single, Surf. Interface Anal., 1990, 15, 215222.

21 N. S. McIntyre and D. G. Zetaruk, Anal. Chem., 1977, 49, 1521-1529.

22 M. Cantoro, S. Hofmann, S. Pisana, V. Scardaci, A. Parvez, C. Ducati, A. C. Ferrari, A. M. Blackburn, K. Y. Wang and J. Robertson, Nano Lett., 2006, 6, 1107-1112.

23 K. Mizuno, K. Hata, T. Saito, S. Ohshima, M. Yumura and S. Iijima, J. Phys. Chem. B, 2005, 109, 2632-2637.

24 H. Ago, Y. Nakamura, Y. Ogawa and M. Tsuji, Carbon, 2011, 49, $176-186$.

25 L. Zhang, L. Dong, W. Yu, L. Liu, Y. Deng, B. Liu, H. Wan, F. Gao, K. Sun and L. Dong, J. Colloid Interface Sci., 2011, 355, 464-471. 
26 T. Murakami, K. Mitikami, S. Ishigaki, K. Matsumoto, K. Nishio, T. Isshiki and H. Harima, J. Appl. Phys., 2006, 100, 094303-1094303-4.

27 F.-Y. Teng, J.-M. Ting, S. P. Sharma and K.-H. Liao, Nanotechnology, 2008, 19, 095607-095612.

28 A. Mathur, S. S. Roy, C. Dickinson and J. A. McLaughlin, Curr. Appl. Phys., 2010, 10, 407-410.

29 W.-Y. Wu, F.-Y. Teng and J.-M. Ting, Carbon, 2011, 49, 4589-4594.

30 R. Y. Zhang, I. Amlani, J. Baker, J. Tresek, R. K. Tsui and P. Fejes, Nano Lett., 2003, 3, 731-735.
31 R. N. Wenzel, Ind. Eng. Chem., 1936, 28, 988-994.

32 A. B. D. Cassie and S. Baxter, Trans. Faraday Soc., 1944, 40, 546551.

33 D. Quere, Annu. Rev. Mater. Res., 2008, 38, 71-99.

34 R. E. Johnson and R. H. Dettre, Adv. Chem., 1964, 43, 136144.

35 B. Balu, V. Breedveld and D. W. Hess, Langmuir, 2008, 24, 47854790.

36 D. Quere and M. Reyssat, Philos. Trans. R. Soc. London, Ser. A, 2008, 366, 1539-1556. 